\title{
Erratum to: Using SPL (Spent Pot-Lining) as an Alternative Fuel in Metallurgical Furnaces
}

\author{
LEI GAO, SINA MOSTAGHEL, SHAMIK RAY, and KINNOR CHATTOPADHYAY
}

DOI: $10.1007 / \mathrm{s} 40553-016-0099-4$

(C) ASM International (ASM) and The Minerals, Metals \& Materials Society (TMS) 2016

\section{Erratum to: METALLURGICAL AND MATERIALS TRANSACTIONS E 3E, 2016, 179-188 DOI: 10.1007/S40553-016-0085-X}

1. In the above article, there is a typo on the title page.The fourth author's name should be Kinnor Chattopadhyay.

2. In the "Introduction" section, lines 8 and 13, "industry" should be "industrial."

3. In the first sentence of "A. Thermodynamic Predictions," the modifications are underlined:

The peak flame temperatures for the combustion of different SPL cases are shown in Figure 4.
4. In the "Conclusions" section, the modifications are underlined:

(1) Injection of SPL (a useful industrial waste), into blast furnaces as an alternative fuel, is a promising and environmentally friendly waste-recycling technique.

(2) Nevertheless, thermodynamic calculation was found to have certain limitations as it ignores the kinetics of combustion.

(3) The combustion of SPL was found to have some prerequisites like blending with natural gas.

LEI GAO, Ph.D. Candidate with the Faculty of Metallurgical and Energy Engineering, State Key Laboratory of Complex Non-Ferrous Metal Resources Clean Utilization, Kunming University of Science and Technology, Kunming, 650093, China, and also Visiting Student with the Department of Materials Science and Engineering, Process Metallurgy and Modeling Group (PM2G), University of Toronto, Toronto, Ontario, M5S 3E4, Canada. SINA MOSTAGHEL, Metallurgist, is with the Technology Development Group, Hatch Ltd., 2800 Speakman Drive, Mississauga, Ontario, L5K 2R7, Canada. SHAMIK RAY, Research Scientist, is with CanmetENERGY, Nature Resources Canada, 1 Haanel Drive, Ottawa, Ontario, K1A 1M1, Canada. KINNOR CHATTOPADHYAY, Assistant Professor, is with the Department of Materials Science and Engineering, Process Metallurgy and Modeling group (PM2G), University of Toronto. Contact e-mail: kinnor.chattopadhyay@utoronto.ca.

The online version of the original article can be found under doi: 10.1007/s40553-016-0085-x.

Article published online September 2, 2016 